\title{
Aftas de la mucosa oral
}

\section{Aphthae of the oral mucosa}

\author{
Rioboo Crespo M*, Bascones Martínez A**
}

\section{RESUMEN}

Objetivos: El afta es la lesión vesiculosa por antonomasia. Es difícil definir un afta verdadera ya que siempre se han llamado aftas a ulceraciones y erosiones de muy diverso origen. Este monográfico revisa la bibliografía más reciente acerca de la etiopatogenia, diagnóstico y tratamiento de éstas lesiones. Material y métodos: Se han revisado los estudios publicados desde 2000 hasta el 2008 mediante Pub-Med. Resultados: Las aftas se definen como un estado vesículo-ulceroso sobre una base eritematosa y fondo amarillento y pasan por una serie de periodos. La etiología aún sigue siendo desconocida. Se le atribuye una causa multifactorial y la literatura cuenta con numerosos estudios que sugieren por un lado, una posible base genética y por otro, la existencia de unos factores predisponentes como el trauma, el estrés, determinados alimentos, desequilibrio hormonal y tabaco; se habla incluso de otros posibles factores predisponentes como la actuación de virus o bacterias, deficiencias vitamínicas y factores inmunológicos. Existen tres formas clínicas de aparición que iremos describiendo tales como las aftas menores, aftas mayores y estomatitis aftosa herpetiforme además de una serie de síndromes que cursan con aparición de aftas a nivel oral y que por ello se denominan síndromes aftosos. El desconocimiento de la etiología y la naturaleza cíclica del proceso complican el tratamiento. Se han sugerido numerosas y diversas terapias contando con una amplia literatura al respecto pero con resultados inconsistentes. El tratamiento debe ser diseñado de forma individual y sintomática y persigue unos objetivos principales: acortar el proceso, evitar recidivas y disminuir los síntomas y tamaño de las úlceras durante el brote.

Palabras clave: Aftas, diagnóstico, tratamiento, aftas recurrentes.

\section{SUMMARY}

Background: Aphthae is a common oral disorder whose definition is difficult due to the general denomination of several ulcerations and erosions as aphthae. The aim of this monographic is to go through the current bibliography on the etiopathogenesis, diagnosis and management of the oral aphthae lesions. Material and methods: We review the published data on Pubmed from 2000 through 2008. Results: Aphtae are defined as an ulcerate-vesiculous lesions over an eritematous base that go by different periods. There is still no conclusive evidence relevant to the etiopathogenesis of this lesions. Aphtae may have a multifactorial cause and the literature suggests either a genetic basis or the existence of predisposing factors such as trauma, stress, food, hormonal imbalance, tobacco and also the role of virus and bacteria, vitamin deficiencies and immunologic factors.

There exist three clinical presentations that are the minor aphthae, major aphthae and herpetiform ulcers. Evenmore, there are some syndromes that occur with oral aphthous which are also called "aphthous syndromes". Since the etiology of the lesions remains unknown and the cyclic nature of the process, it makes difficult to have a definitive treatment. Numerous and miscelany therapies have been proposed but the results found on

* Máster de Periodoncia del departamento III. Facultad de Odontología. Universidad Complutense de Madrid. España.

** Catedrático del departamento III. Facultad de Odontología. Universidad Complutense de Madrid. España. 
the vast literature are inconsistent. Thus, the therapy should be tailored to each patient as individually. The goal of this symptomatic therapy is to decrease symptoms, reduce ulcer number and size and increase disease-free period.

Key words: Aphthae, diagnosis, treatment, recurrent aphthous.

Fecha de recepción: 11 de noviembre de 2009.

Aceptado para publicación: 20 de noviembre de 2009.

Rioboo Crespo M, Bascones Martínez A. Aftas de la mucosa oral. Av. Odontoestomatol 2011; 27 (2): 63-74.

\section{INTRODUCCIÓN}

La palabra afta procede del término griego "Aphtay" y significa quemadura. Es la lesión vesiculosa por antonomasia. Se trata de una lesión elemental elevada de contenido líquido, claro, que se localizan en el epitelio y que generalmente no dejan cicatriz, excepto el afta de Sutton. Es difícil definir un afta verdadera ya que desde los albores de la medicina se llamaron aftas a ulceraciones y erosiones de muy diverso origen. El nombre de afta lo llevan diversos procesos totalmente diferentes: traumática, vulgar, de Bednar, neurótica etc, las cuales tienen características clínicas, histológicas, evolutivas, pronósticas y terapéuticas diferentes.
Como ya definió Crispan desde 1973, es necesario distinguir las aftas verdaderas, de las aftoides, que son producidas por virus y de las aftosis, que son procesos sistémicos que cursan con aftas o aftosis. Desde entonces, un afta verdadera ha sido definida por una serie de características fundamentales y características secundarias tal y como exponemos en la tabla 1.

\section{PERIODOS}

Las aftas se definen como un estado vesículo-ulceroso sobre una base eritematosa y fondo amarillento y pasan por una serie de periodos.

\begin{tabular}{|c|c|c|}
\hline \multicolumn{3}{|c|}{ TABLA 1.- CARACTERÍSTICAS DE LAS AFTAS VERDADERAS } \\
\hline \multirow{2}{*}{ FUNDAMENTALES } & \multicolumn{2}{|c|}{ SECUNDARIAS } \\
\hline & Tipo leve, erosivo, no cicatricial & Tipo severo, ulcerado, cicatricial \\
\hline $\begin{array}{l}\text { - Pérdida de sustancia } \\
\text { - Aparición súbita, } \\
\text { aguda } \\
\text { - Dolor quemante } \\
\text { - Inicialmente necrótica } \\
\text { - Recidivante } \\
\text { - Localización: } \\
\text { mucosa. }\end{array}$ & $\begin{array}{l}\text { Número: } 2 \text { o } 3 \\
\text { Loc: Muc. labial, yugal lengua } \\
\text { Forma: Oval } \\
\text { Tamaño: No más de } 0,5 \mathrm{~cm} \\
\text { Borde: Algo indurado, eritema } \\
\text { Prof: Erosivo, apenas ulcerada } \\
\text { Fondo: Necrótico } \\
\text { Evolución: Cura en pocos días } \\
\text { Secuela: Sin cicatriz }\end{array}$ & $\begin{array}{l}\text { Menos numerosas } \\
\text { Diferentes } \\
\text { Irregular } \\
\text { Sobrepasa } 1 \mathrm{~cm} \\
\text { Elevado } \\
\text { Mayor profundidad. Ulceraciones } \\
\text { Necrótico } \\
\text { Mayor duración } \\
\text { Cura dejando cicatrices }\end{array}$ \\
\hline
\end{tabular}




\section{PERIOdo VESICULOSO}

Es un periodo difícil de visualizar durante el cual, el afta presenta un diámetro de 2 a $5 \mathrm{~mm}$ y elevación del epitelio que recubre un punto amarillento rodeado por un halo eritematoso y pasados 2-3 días aparece una cierta opacidad.

\section{PERIOdo UlCERoso}

Ocurre tras el desgarro del techo epitelial (1). El fondo presenta detritus celulares y fibrina e infiltrado de neutrófilos en los márgenes y en profundidad. Durante este periodo, proliferan los fibroblastos en la base y empieza la angiogénesis. A su vez, el tejido de granulación va rellenando el fondo y la mucosa que rodea la vesícula se hunde. Es un periodo muy doloroso, durante el cual los pacientes refieren sensación de quemazón, dificultad en masticación, deglución e incluso fonación. Pueden darse linfadenitis regionales.

\section{PERIODO DE CICATRIZACIÓN}

La úlcera se limpia y reepiteliza sin dejar cicatriz.

\section{INMUNOPATOGÉNESIS}

En la etiopatogénesis está involucrada una respuesta inmune predominantemente celular en la que las células $\mathrm{T}$ y especialmente la producción del factor de necrosis tumoral $\alpha$ (TNF $\alpha$ ) juegan un papel importante. El TNF $\alpha$ induce la inflamación debido a sus efectos sobre las células endoteliales de adhesión y la quimiotaxis de los neutrófilos. Además, otras citoquinas como las interleuquinas -2; -10 o las células NK, activadas por la IL-2, tienen un papel en la aparición de las aftas (2, 3).

\section{ETIOPATOGENIA}

La etiología aún sigue siendo desconocida. Se le atribuye una causa multifactorial y autores como Scully, en el consenso del 2003 hablan, por un lado, de una posible base genética e historia familiar y por otro, de unos factores predisponentes como el trauma, el estrés, determinados alimentos, desequilibrio hormo- nal y tabaco (4). La bibliografía es controvertida y otros autores hablan además de otros posibles factores predisponentes como la actuación de virus o bacterias (5), deficiencias vitamínicas (6) y factores inmunológicos (7).

\section{HERENCIA}

Uno de los primeros autores en estudiar la heredabilidad de las aftas recurrentes fue Ship y col. Estos observaron, tras el estudio de 815 familias, que más del $45 \%$ de pacientes con aftas recurrentes tenían parientes de primer grado afectados y que era más severo y aparecían más temprano en pacientes con historia familiar que aquellos que no la tenían. Aunque los autores no descartan una posible herencia recesiva, sugieren que la tendencia a tener aftas de carácter recesivo o dominante aumenta debido a factores desencadenantes (8).

Además, han sido numerosas las publicaciones asociando la aftosis recidivante con determinados antígenos del HLA como el HLA-DR2 (9) o el HLA-B12 (10).

\section{FACTORES INMUNOLÓGICOS}

Son numerosas las hipótesis que han sido arrojadas relacionando el sistema inmune con las aftas. Por un lado, autores defienden la existencia de niveles aumentados de inmunoglobulinas como la IgG, IgA e $\operatorname{IgE}(7)$, otros hablan de una posible reactividad cruzada de antígenos de la mucosa oral y antígenos bacterianos (11), igualmente de una posible desproporción de la relación de los linfocitos CD4 y CD8 (1). Esta última teoría sostiene el aumento de los LCD4 en la fase preulcerosa (2/1) y fase de curación (10/1) y el aumento de los LCD8 en la fase ulcerosa (10/1). Las aftas han sido asociadas igualmente con un aumento del TNF- $\alpha$ (2) y descenso del VEGF (12) así como un posible papel de las moléculas de adhesión (aumento de VCAM, E-selectina e I-CAM) (13).

\section{FACTORES PSICOLÓGICOS}

La aparición de un episodio de aftas ha sido comúnmente asociado con la tensión emocional. 
Sugiriendo que el estrés y su posible efecto sobre el sistema inmune sea una causa de la aparición de aftas. Determinados estudios han tenido como objetivo la medida de los niveles de cortisol en saliva y suero en pacientes afectados con estomatitis aftosa recidivante observando que estos tenían de forma estadísticamente significativa mayores concentraciones de cortisol y niveles de ansiedad que los controles $(14,15)$.

\section{TRAUMATISMOS}

El trauma actuaría como un factor precipitante provocando la aparición de úlceras en pacientes con estomatitis aftosa recidivante. Los traumas más comunes son el trauma por el cepillado, alimentos duros, anestesia superficial brusca, dientes, aparatos y mordeduras.

\section{FACTORES ALIMENTARIOS Y DEFICIENCIAS VITAMÍNICAS}

Algunos alimentos pueden desencadenar un brote de aftas (16). Entre estos, se han descrito la leche de vaca, el chocolate, queso, crustáceos, café, cereales, frutos secos e incluso la piel del tomate y la harina (contiene gluten) y, además, se han observado mejorías clínicas en pacientes con aftas re-

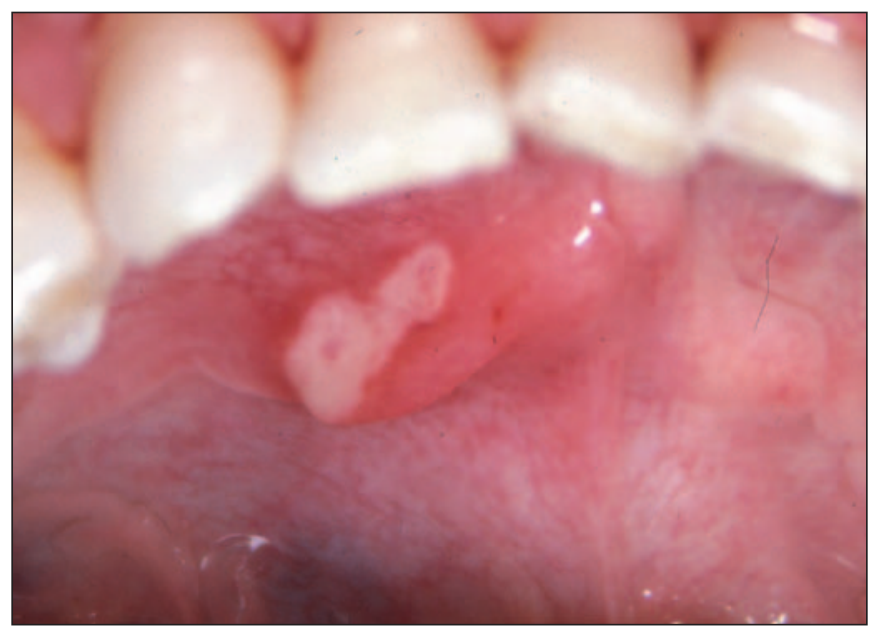

Fig. 1. Afta traumática. currentes al excluir determinados alimentos de la dieta (17).

Deficiencias vitamínicas como la vitamina B12, que aparece con mayor asociación (6), el ácido fólico, el hierro así como bajos niveles de vitaminas A, E y C (18) han sido asociados con episodios de aftas.

\section{TABAQUISMO}

Los pacientes que sufren aftas recurrentes suelen ser no fumadores (19). La incidencia de aftas es menor en fumadores debido a la hiperqueratinización que produce el tabaco. Se ha observado que en pacientes que dejan de fumar la incidencia de aftas aumenta, mientras que en los que retoman el tabaco ésta se controla (20). Además, se ha observado que aquellos pacientes en terapia antitabaco (reemplazo de la nicotina), la incidencia de aftas es menor que los que no siguen ninguna terapia (21).

\section{FACTORES ENDOCRINOS}

En etapas premenstruales se ha descrito una mayor frecuencia de aparición de las aftas y, en cambio, una disminución en los primeros meses de embarazo. Algunos autores sugieren que en algunos pacientes éstas disminuyen durante el tratamiento con contraceptivos orales o durante el embarazo (22). Otros no encuentran asociación alguna entre la aparición de aftas y la menstruación, embarazo o menopausia (23).

\section{FACTORES VÍRICOS Y BACTERIANOS}

Estos actuarían como sobreinfección de la mucosa previamente ulcerada. El origen viral no ha sido demostrado, además, histológicamente, no se observa una degeneración balonizante y reticular característica del herpes.

En cuanto a la presencia de bacterias, se ha observado más frecuentemente en pacientes con dispepsia. Un alto porcentaje de aftas en pacientes en los que se erradicó helicobacter pylori desaparecieron (5). 


\section{FORMAS CLÍNICAS}

\section{ESTOMATITIS AFTOSA RECURRENTE (RAS)}

La aparición del RAS suele darse durante la infancia. La frecuencia de aparición y severidad disminuye con la edad. Alrededor del $80 \%$ de la población que la sufre la desarrollan antes de los 30 años.

Existen tres formas clínicas de aparición que iremos describiendo una a una (Tabla 2).

\section{Aftas menores}

También llamadas Aftas de Mikulicz o úlceras aftosas leves. Aparecen en el 75\%-85\% de los casos de RAS (24). Son pequeñas úlceras bucales de 5 a $10 \mathrm{~mm}$ redondas u ovaladas delimitadas y no dolorosas rodeadas por un halo eritematoso y poco profundas. Pueden localizarse en todas las zonas no queratinizadas de la cavidad oral incluyendo la mucosa labial, vestibular, suelo de la boca y la zona ventral o lateral de la lengua. La duración es de 10 a 14 días y sus recurrencias varían pero en general aparecen cada 2-3 meses. Este tipo de aftas cura de forma más lenta que cualquier herida oral lo que podría estar asociado a la presencia de un infiltrado linfocítico intenso (25).

\section{Aftas mayores}

También denominada afta crónico habitual o simple recidivante. Clásicamente denominada periadenitis

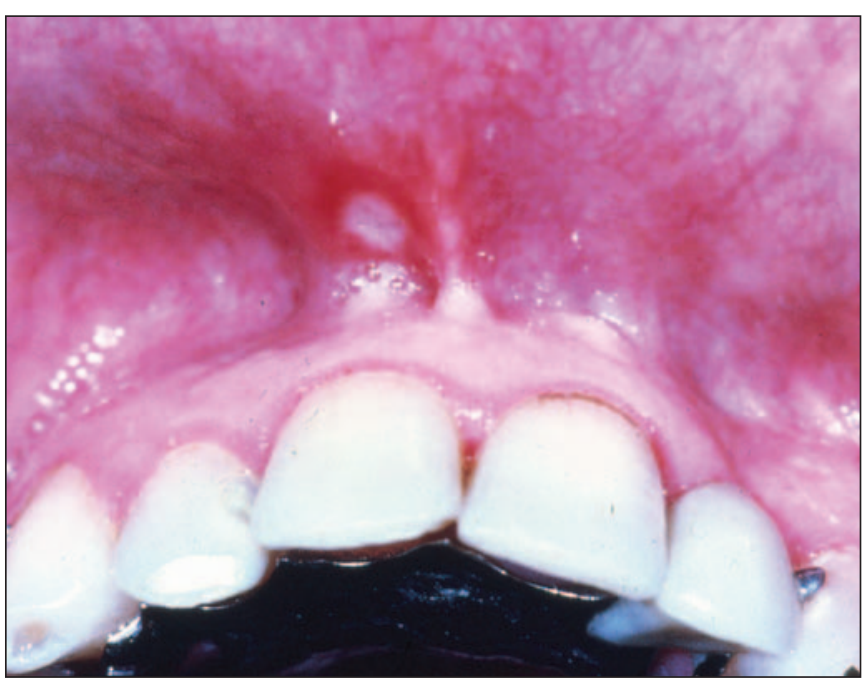

Fig. 2. Afta menor.

necrótica recidivante de Sutton (1911) o gran estomatitis aftosa cicatricial. Sutton describió la existencia de un infiltrado inflamatorio alrededor de las glándulas accesorias de la mucosa oral con la lámina basal conservada.

La enfermedad pasa por varios estadios: un primer estadio nodular, un segundo estadio ulceroso y un tercer y último estadio cicatricial ya que las úlceras curan dejando cicatrices de carácter fibroso y retráctil. Son aproximadamente el 10 al $15 \%$ de la RAS. Aparecen en la época media de la vida tras la pubertad. Son redondeadas u ovaladas de mayor tamaño que excede de $1 \mathrm{~cm}$ con márgenes claramente delimitados pero irregulares. La ulceración es más profunda, el dolor muy intenso y suele aparecer 1 o 2 al

TABLA 2.- FORMAS CLÍNICAS DEL RAS (SCULLY, CONSENSO DEL 2003)

\begin{tabular}{|l|c|c|c|}
\hline \multicolumn{3}{|c|}{ CARACTERÍSTICAS DE LAS PRESENTACIONES CLÍNICAS DE LAS AFTAS } \\
\hline \multirow{2}{*}{ CARACTERÍsTICAS } & \multicolumn{3}{|c|}{ MANIFESTACIÓN CLÍNICA } \\
\cline { 2 - 4 } & Afta menor & Afta mayor & Úlceras herpetiformes \\
\hline Tamaño (mm) & $5-10$ & $>10$ & $<5$ \\
Duración (días) & $10-14$ & 2 semanas & $10-14$ \\
Dolor & No & $\mathrm{Si}$ & No \\
Prevalencia & $75-85$ & $10-15$ & $5-10$ \\
\hline
\end{tabular}



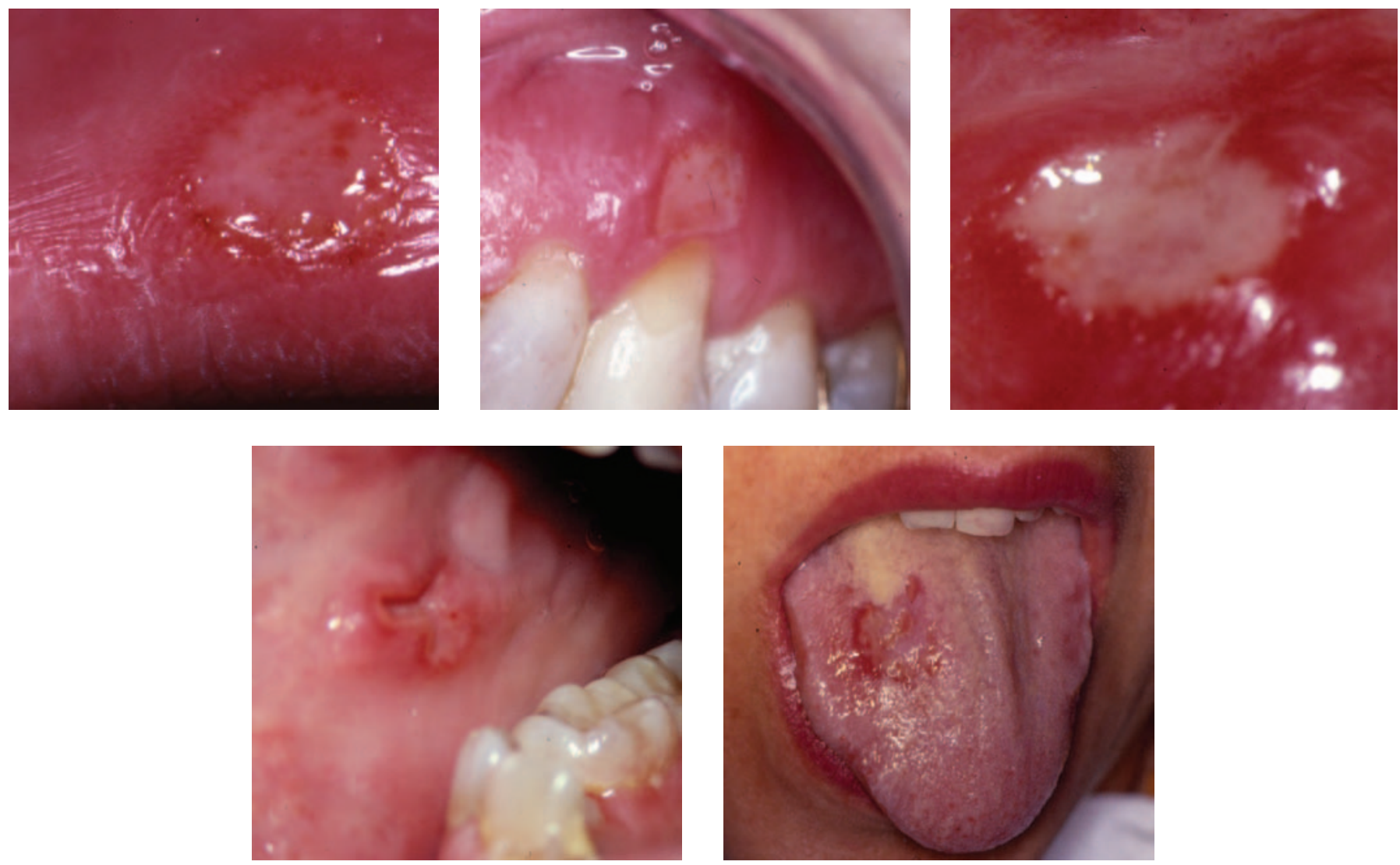

Fig. 3. Aftas mayores.

mismo tiempo. Aparecen en mucosa labial, paladar blando e istmo de las fauces. La cicatrización es más larga, puede durar semanas o meses. A veces el proceso inicial se acompaña con fiebre, disfagia y malestar general (24).

\section{Estomatitis aftosa herpetiforme}

Este tipo constituye sólo el $5-10 \%$ de los casos de RAS. Aparecen múltiples (de 5 a 100) úlceras pequeñas (1-3 mm), redondas y dolorosas agrupadas en racimos similares a las úlceras del herpes simple y localizadas en cualquier parte de la cavidad oral. Tienden a unirse formando úlceras más grande tras varios días (10-14 días). Suelen aparecer en la tercera edad y son más comunes en mujeres. La mayoría de los pacientes tienen sólo de 2 a 4 recurrencias por año lo que se denomina aftosis simple. Algunos presentan una actividad continua desarrollando lesio- nes nuevas al cicatrizar las antiguas o con úlceras asociadas a enfermedades sistémicas (aftosis compleja) (24).

\section{AfTA DE BEDNAR}

También llamada afta pterigoide. Las úlceras que aparecen son superficiales y bilaterales generalmente en mucosa de la región palatina. En recién nacidos, la causa es la presión del pezón contra el paladar. En el adulto suele producirse por algún trauma como el del espejo de exploración. Cura espontáneamente.

\section{SÍNDROMES AFTOSOS}

Existe un conjunto de síndromes denominados "síndromes aftosos" ya que cursan con la aparición de 
aftas y por lo tanto éstas no pueden considerarse como aftas verdaderas.

\section{Síndrome de Behcet (1937)}

Enfermedad reumática crónica que cursa con vasculitis sistémica. De carácter recidivante, se caracteriza por la aparición de la triada de signos clínicos de aftas bucales, úlceras genitales (65\%) y alteraciones oculares (80\%). Además para confirmar la enfermedad deben aparecer lesiones cutáneas o presentar teste de patergia positivo (1990). Pueden existir igualmente alteraciones gastrointestinales, pulmonares, musculares y hematológicas. Las aftas son recidivantes apareciendo al menos 3 veces al año y son el signo inicial de la enfermedad en un $70 \%$ de los casos aproximadamente (26). La evolución es lenta crónica y progresiva. El tratamiento es la administración de corticoides y citostáticos.

\section{Afta de Newman}

También denominada "aftosis bipolar de Newman" (1895) ya que cursa con la aparición de aftas a nivel bucal y vulvar (70-80\%) (27). Muchos autores consideran que se trata de una forma frustrada del síndrome de Behcet (28). Es más frecuente en mujeres. Las aftas son grandes, necróticas y, presentan bordes elevados y una base infiltrada. Éstas se asemejan a las de la periadenitis necrótica de Sutton o aftas mayores verdaderas. No dan manifestaciones generales ni aparecen en otras localizaciones, curan difícilmente y persisten en el tiempo.

\section{Síndrome de Reiter}

Enfermedad reumática que se caracteriza por la presencia de la triada ureítis, artritis y conjuntivitis. Además, aparecen en un $10 \%$ de los casos, aftas en la cavidad bucal en forma lesiones circinadas o pequeñas vesículas opacas distribuidas en todas las regiones. En la lengua, las lesiones se parecen a las de la lengua geográfica (29). Generalmente aparece en jóvenes (varones de 20-40 años de edad) y su aparición en niños y mujeres es rara. El síndrome de Reiter aparece como complicación de procesos in- fecciosos aunque se habla igualmente de una base genética y de factores ambientales de este modo, autores sostienen la teoría de la actuación de diversos factores genéticos (como el antígeno HLA-B27) y ambientales que causan una reactividad inmunológica anormal ante ciertos patógenos bacterianos, por lo que muchos expertos actualmente lo describen con el término artritis reactiva (30).

\section{DIAGNÓSTICO}

El diagnóstico de RAS se realiza en base a la historia y criterios clínicos ya que no existen tests de laboratorio específicos. Por lo tanto, las características clínicas serán la base para el diagnóstico diferencial de condiciones que cursan con ulceraciones. El diagnóstico mediante laboratorio se realizará para descartar alteraciones hematológicas o sistémicas.

\section{Diagnóstico diferencial}

Se realiza fundamentalmente con condiciones que mimetizan úlceras y aftas bucales como determinadas infecciones víricas (31), lesiones por agentes físicos y exposición a determinados fármacos. Del mismo modo, alteraciones inmunológicas y recuentos de linfocitos CD4 T inferiores a 100 células por mililitro así como en pacientes VIH positivos o formas de neutropenia pueden observarse aftas. Algunas enfermedades gastrointestinales como la celiaquía, enfermedad de Crohn y la colitis ulcerosa pueden cursar con aftas bucales. También es necesario diferenciar el diagnóstico de un posible síndrome de PFAPA (fiebre periódica, aftas, faringitis y adenitis) que se observa de forma ocasional en niños con RAS (4) (Cuadro 1).

\section{TRATAMIENTO}

El desconocimiento de la etiología y la naturaleza cíclica del proceso hacen que un diseño correcto de ensayos clínicos controlados a doble ciego sean difíciles de realizar y por lo tanto que no haya un tratamiento definitivo. Se han sugerido numerosas y diversas terapias de las cuales, muy pocas han sido evaluadas en ensayos clínicos bien diseñados 


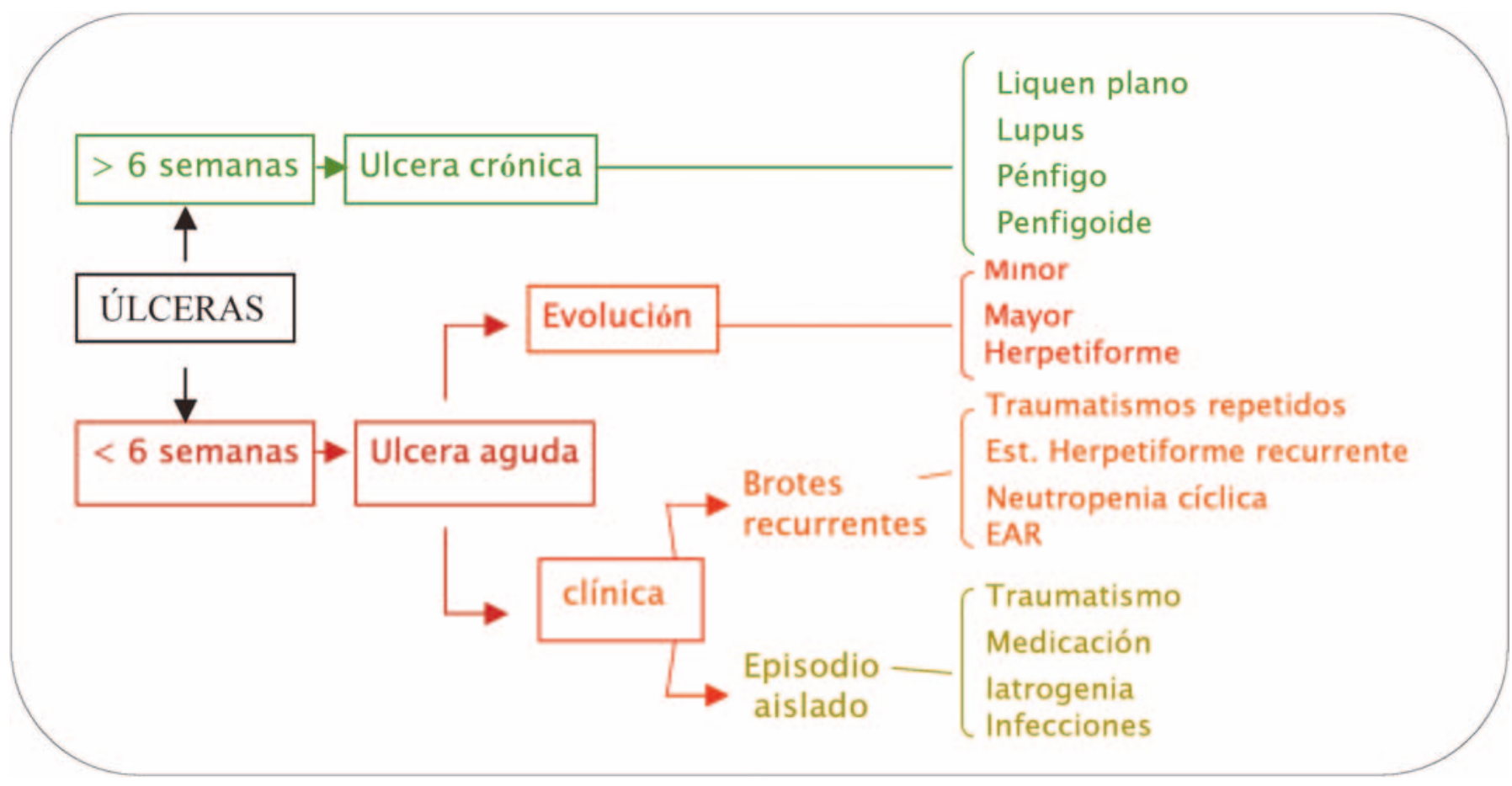

Cuadro 1. Diagnóstico diferencial.

y por lo tanto aunque sea muy amplia la literatura que existe sobre tratamientos de las aftas bucales, ésta cuenta con resultados inconsistentes. El tratamiento debe ser diseñado de forma individual para cada uno de los pacientes y de forma sintomática en el que los principales objetivos de la terapia son: acortar el proceso, evitar recidivas y disminuir los síntomas y tamaño de las úlceras durante el brote (Tabla 3).

\section{LÍNEAS DE TRATAMIENTO}

\section{Primera línea de tratamiento}

\section{Tratamiento local}

Geles tópicos, cremas y pomadas son ampliamente utilizados durante la fase inicial. Son numerosos los productos que existen en el mercado y que son administrados de forma empírica en las farmacias (Tabla 4). Éstos se componen fundamentalmente de corticoides tópicos y de otras sustancias como el amlexanox (5\%), prostaglandinas, interferón, doximicina-cianoacrilato e hidropropilcelulosa. Inclu-
TABLA 3.- TRATAMIENTO DE LAS AFTAS

\begin{tabular}{|l|l|}
\hline \multicolumn{2}{|l|}{ Tratamientos con investigación reciente } \\
\hline Aciclovir & Irsogladine Maleate \\
\hline Amelexanox tópico* & Levamisol \\
\hline Azelastine & Nicotina \\
\hline Chlorhexidina & Pentoxifylina \\
\hline Colchicina & $\begin{array}{l}\text { Photophoresis de } \\
\text { Oxolin }\end{array}$ \\
\hline Corticoesteroids & Relaxation/Imagery \\
\hline Dapsone & Shrak liver oil \\
\hline Diciofenac in Hyaluronan* & Sucralfato \\
\hline Doxymicina-Cyanoacrylato & Tetraciclinas \\
\hline Eupetorium Laevigatum & Thalidomida* \\
\hline Helium-Neon Laser & Triclosan \\
\hline Interferon-Alpha & Ultrasonidos \\
\hline
\end{tabular}

* Ensayos controlados. 


\section{TABLA 4.- PRODUCTOS DISTRIBUIDOS} EN EL MERCADO (31)

\begin{tabular}{|c|c|}
\hline Type & Therapeutic Agent \\
\hline Barrier Pastes & $\begin{array}{l}\text { - Orabase } \\
\text { - Orabase B (benzocaine 20\%) } \\
\text { - Honey }\end{array}$ \\
\hline Bioadhesive Discs & $\begin{array}{l}\text { - CankerMtots GX (Glycymhiza excract) } \\
\text { - Carington Orapatch (abe vera hydrogel) } \\
\text { - Canker Cover } \\
\text { - Orajel protective mouth sore ciscs (benzocaine) }\end{array}$ \\
\hline Fllm-forming Geis & $\begin{array}{l}\text { - Orabase Sootho-N-Sear" } \\
\text { - Zlactin } \\
\text { - Zlactin-B (benzocaine 10\%) } \\
\text { - Kank-A (benzocaine 20\%) }\end{array}$ \\
\hline $\begin{array}{l}\text { Local Anesthetics } \\
\text { (benzocaine) }\end{array}$ & 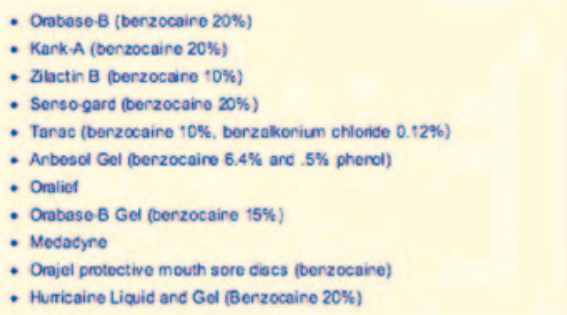 \\
\hline Oxygenating Agents & $\begin{array}{l}\text { - Orajel perioseptic } \\
\text { - Amosan (Sodum Perborate Monohydate) } \\
\text { - Peruxyl mouthinse } \\
\text { - Peroxyl Onal Spot Treatment Gel (1.5\% hydrogen peroxide in gel base) } \\
\text { - Cankaid Rinse (carbamide peroxide } 10 \% \text { ) } \\
\text { - Gy-Oxide (carbamide peroxide } 10 \% \text { ) } \\
\text { - Peniobav (carbamide peroxide } 10 \% \text { ) } \\
\text { - Orajel Perioseptic (carbamide peroxide } 15 \% \text { ) }\end{array}$ \\
\hline Type & Therapeutic Agent \\
\hline $\begin{array}{l}\text { Other Antiseptic Mouth } \\
\text { Rinses }\end{array}$ & $\begin{array}{l}\text { - Chlorhexidine* } \\
\text { - Chlorheximod" } \\
\text { - Triclosan } \\
\text { - Benzydamine hydrochloride } \\
\text { - Oilam* } \\
\text { - Oraldere } \\
\text { - Listerine } \\
\text { - Viacent } \\
\text { - Plax } \\
\text { - Biotone maithwash (antibactorial erzymes) }\end{array}$ \\
\hline Herts & $\begin{array}{l}\text { - CankerMots GX (Glycymhiza extract) } \\
\text { - Many others }\end{array}$ \\
\hline Off-Label Applications & $\begin{array}{l}\text { - Znc gluconate lozenges } \\
\text { - Hydrogen peroxice } \\
\text { - Suleraftate paste } \\
\text { - Dipherhydramine Hydrochionice (Benaciyl synp) with Kaopectate anc } \\
\text { Maalox }\end{array}$ \\
\hline
\end{tabular}

tasona, tetraciclina, clorexhidina, triclosán, hidrocortisona acuosa o triamcinolona.

Los antiinflamatorios esteroideos actuarían reduciendo la exudación de los leucocitos y de componentes del plasma, manteniendo la integridad de la membrana, inhibiendo la liberación de lisosomas por los granulocitos y de la fagocitosis e incluso inhibiendo la formación de cicatriz y a dosis altas teniendo efecto en la formación de anticuerpos (33).

Autores han sugerido que en el tratamiento de las aftas, el grado de potencia de los corticoides a utilizar puede oscilar entre la triamcinolona al clobetasol.

Los autores recomiendan que para promover la curación de las úlceras recurrentes los medicamentos tópicos deben ser aplicados directamente sobre la lesión manteniendo el material en contacto directo el mayor tiempo posible con una barrera que permita la permanencia. Dale y col, en un estudio que comparó el uso tópico de triamcinolona acetónido $0,025 \%$ con clorhexidina $0,12 \%$ cubiertos con una barrera de isobutil cianoacrilato, no se observó diferencias estadísticamente significativas al comparar los tratamientos entre sí aunque si que las hubo al compararlos con el placebo. Otros estudios, como el de Losada-Nur 1991, sugieren que el clobetasol propionato al $0,025 \%$ puede igualmente dar excelentes resultados.

La tendencia que se observa en los resultados de los estudios que valoran el tratamiento tópico con corticoides es que éstos son capaces de disminuir el tiempo de cicatrización de las úlceras aftosas y de mejorar el dolor (33).

Otras terapias utilizadas son la cauterización química, electrocauterización y ultrasonidos, anestésicos locales e inyecciones de corticoides in sito. El tratamiento con violeta de genciana, descrita por Screder en 1983 ha sido ampliamente utilizada.

\section{Tratamiento sistémico}

En esta fase es necesario tratar los déficit nutricionales y hematológicos presentes, evitar los alimentos que produzcan reacciones alérgicas y tratar las enfermedades sistémicas subyacentes además del con- so el ácido hialurónico aplicado de forma tópica ha resultado beneficioso (32). Los enjuagues también se utilizan en úlceras menores y pueden formularse con diversos productos como el sucralfato, dexame- 
trol del estrés. Se han descrito casos en los que se observa una curación completa únicamente con la administración de vitamina B12 en pacientes que presentaban déficits (34).

El tratamiento sistémico con corticoides no se considera apropiado por la posibilidad de incrementar el riesgo a candidiasis, atrofia de la mucosa, supresión adrenal o intolerancia a la terapia sistémica.

\section{Segunda línea de tratamiento}

Indicada en casos graves y recidivantes tras tratamiento de primera línea. Debido al no control de los síntomas tras la primera fase y la gravedad de los mismos, se requiere una forma de terapia más agresiva. Los corticoides sistémicos tales como la prednisona son una indicación e incluso se ha llegado a combinar con azatiopina. Es de crucial importancia en este punto consultar a un especialista.

\section{Tercera línea de tratamiento}

Se trata de un tratamiento inmunomodulador para casos severos de aftas. La talidomida y la pentoxifilina, inhibidores del FNT, se utilizan en dosis variables dependiendo de la severidad de las lesiones y tolerancia del paciente. Así mismo se han utilizado levamisol, colchicina, ciclosporina, pentoxifilina entre otros.

\section{Terapia coadyuvante}

Tratamiento de soporte en casos de aftas persistentes y dolorosas en el que se emplean analgésicos tópicos y suplementos vitamínicos y proteínicos. En esta fase es importante insistir en la higiene oral para evitar agentes precipitantes de lesiones de aftas y recomendar el uso de lauril sulfato.

\section{CONCLUSIONES}

La aparición de aftas orales es una alteración frecuente cuya etiopatogénesis es desconocida. No existen tests diagnósticos por lo que éste se realiza mediante la clínica. Existen factores como el estrés, el trauma o la dieta que pueden predisponer a la aparición de aftas. Nuestro papel fundamental es identificar dichos factores predisponentes y tratar de eliminarlos además de informar correctamente al paciente de su condición especialmente haciendo hincapié en el hecho de que no es contagioso y que no está producido por el herpes simple como muchos piensan.

Los fármacos tópicos o sistémicos antiinflamatorios $\mathrm{y}$, en concreto, los corticoides son los indicados debido al carácter inflamatorio y doloroso del proceso. Por lo tanto, además de una intervención temprana, que es fundamental, los esteroides tópicos utilizados durante un corto periodo de tiempo son seguros y deben de utilizarse como primera línea de tratamiento $(35,36)$.

\section{BIBLIOGRAFÍA}

1. Albanidou-Farmaki E, et al. Detection, enumeration and characterization of $\mathrm{T}$ helper cells secreting type 1 and type 2 cytokines in patients with recurrent aphthous stomatitis. Tohoku J Exp Med 2007;212(2):101-5.

2. Natah SS, et al. Immunolocalization of tumor necrosis factor-alpha expressing cells in recurrent aphthous ulcer lesions (RAU). J Oral Pathol Med 2000;29(1):19-25.

3. Sun A, et al. Mechanisms of depressed natural killer cell activity in recurrent aphthous ulcers. Clin Immunol Immunopathol 1991;60(1):83-92.

4. Scully C, Gorsky M, Lozada-Nur F. The diagnosis and management of recurrent aphthous stomatitis: a consensus approach. J Am Dent Assoc 2003; 134(2):200-7.

5. Brailo V, Boras VV, Cekic-Arambasin A. (Recurrent aphthous ulcerations: analysis of predisposing factors in 68 patients). Lijec Vjesn 2007;129(12):4-7.

6. Koybasi S, et al. Recurrent aphthous stomatitis: investigation of possible etiologic factors. Am J Otolaryngol, 2006;27(4):229-32. 
7. Brozovic S, Vucicevic-Boras V, Bukovic D. Serum $\operatorname{Ig} A, \operatorname{Ig} G, \operatorname{Ig} M$ and salivary $\operatorname{Ig} A$ in recurrent aphthous ulceration. Coll Antropol, 2001;25(2): 633-7.

8. Shi II. Inheritance of aphthous ulcers of the mouth. J Dent Res, 1965;44(5):837-44.

9. Lehner T. Immunologic aspects of recurrent oral ulcers. Oral Surg Oral Med Oral Pathol, 1972;33(1):80-5.

10. Sun A, et al. Some specific human leukocyte antigen (HLA)-DR/DQ haplotypes are more important than individual HLA-DR and -DQ phenotypes for the development of mucocutaneous type of Behcet's disease and for disease shift from recurrent aphthous stomatitis to mucocutaneous type of Behcet's disease. J Oral Pathol Med 2001;30(7):402-7.

11. Hoover. Humoral responses and cross-reactivity to viridans streptococci in recurrent aphthous ulceration. j Dent Res 1986;65(8):1101-4.

12. Brozovic S, et al. Salivary levels of vascular endothelial growth factor (VEGF) in recurrent aphthous ulceration. J Oral Pathol Med 2002; 31(2):106-8.

13. Richards DW, et al. Expression of laminin 5, fibronectin,epithelium-associated integrins in recurrent aphthous ulcers. J Dent Res 1996;75 (7):1512-7.

14. McCartan BE, Lamey PJ, Wallace AM. Salivary cortisol and anxiety in recurrent aphthous stomatitis. J Oral Pathol Med 1996;25(7):357-9.

15. Albanidou-Farmaki E, et al. Increased anxiety level and high salivary and serum cortisol concentrations in patients with recurrent aphthous stomatitis. Tohoku J Exp Med 2008; 214(4):291-6.

16. Eversole LR, Shopper TP, Chambers DW. Effects of suspected foodstuff challenging agents in the etiology of recurrent aphthous stomatitis. Oral Surg Oral Med Oral Pathol, 1982;54(1):33-8.
17. Nolan A, et al. Recurrent aphthous ulceration and food sensitivity. J Oral Pathol Med 1991;20 (10):473-5.

18. Saral Y, et al. Assessment of salivary and serum antioxidant vitamins and lipid peroxidation in patients with recurrent aphthous ulceration. Tohoku J Exp Med 2005;206(4):305-12.

19. Tuzun B, et al. Recurrent aphthous stomatitis and smoking. Int J Dermatol 2000;39(5):358-60.

20. Marakoglu K, et al. The recurrent aphthous stomatitis frequency in the smoking cessation people. Clin Oral Investig 2007;11(2):149-53.

21. Grady D, et al. Smokeless tobacco use prevents aphthous stomatitis. Oral Surg Oral Med Oral Pathol 1992;74(4):463-5.

22. Ferguson MM, et al. Progeston therapy for menstrually related aphthae. Int J Oral Surg 1978; 7(5):463-70.

23. McCartan BE, Sullivan A. The association of menstrual cycle, pregnancy,menopause with recurrent oral aphthous stomatitis: a review and critique. Obstet Gynecol 1992;80(3 Pt 1): 455-8.

24. Rogers RS. 3rd, Recurrent aphthous stomatitis: clinical characteristics and associated systemic disorders. Semin Cutan Med Surg 1997;16(4): 278-83.

25. Eversole LR. Immunopathology of oral mucosal ulcerative, desquamative,bullous diseases. Selective review of the literature. Oral Surg Oral Med Oral Pathol 1994;77(6):555-71.

26. McDonald DR, et al. Behcet's disease. Cmaj 2007;176(9):1273-4.

27. Gupta S, et al. Bipolar aphthosis presenting as mutilating genital ulcers in women. Indian $\mathrm{J}$ Dermatol Venereol Leprol 2004;70(6):357-60.

28. Boyvat A, Ekmekci P, Gurgey E. Bipolar aphthosis. A forme fruste of Behcet's disease. Long term 
follow-up of 26 cases. Adv Exp Med Biol 2003; 528:321-2.

29. Wu and Schwartz. Reiter's syndrome: the classic triad and more. J Am Acad Dermatol 2008;59 (1):113-21.

30. Keynan Y, and Rima. Reactive arthritis - the appropriate name. Isr Med Assoc J 2008;10(4): 256-8.

31. Bascones Martínez A. Afectación oral de las enfermedades comunes en la infancia con carácter exantemático. Av Odotoestomatol 2006;22(3): 163-170.

32. Nolan A, et al. The efficacy of topical hyaluronic acid in the management of recurrent aphthous ulceration. J Oral Pathol Med 2006;35(8):461-5.

33. Quijano D, Rodríguez M. (Topical corticosteroids in recurrent aphthous stomatitis. Systematic review.). Acta Otorrinolaringol Esp 2008;59(6): 298-307.
34. Volkov I, et al. Case report: Recurrent aphthous stomatitis responds to vitamin B12 treatment. Can Fam Physician, 2005;51:844-5.

35. Muñoz-Corcuera M, Esparta. Gómez G, GonzálezMoles MA, Bascones-Martínez A. Oral ulcers. Clinical aspects. A tool for dermatologist. Part I: Acute ulcers. Experimenta Dermatology (en prensa).

36. Muñoz-Corcuera M, Esparta. Gómez G, GonzálezMoles MA, Bascones-Martínez A. Oral ulcers. Clinical aspects. A tool for dermatologist. Part II: Chronic ulcers. Experimenta Dermatology (en prensa).

\section{CORRESPONDENCIA}

María Rioboo Crespo

Departamento III

Facultad de Odontología

Universidad Complutense de Madrid Ciudad Universitaria.

28040 Madrid. España

E-mail: mariarioboocrespo@yahoo.es 